\title{
CHAPTER 88
}

SHEAR VELOCITY IN A TIDAL ESTUARY

by

A. Roy Hallıwell

Lecturer, Dept. of Civil Eng., Liverpool University, England

and

Brian A. O'Connor

Research Fellow, Dept. of Civil Eng., Liverpool University, England

\section{ABSTRACT}

A study involving the determination of the bed shear stress and thence shear velocity in the Narrows of the River Mersey (a well mixed tidal estuary) 1s described. The two dimensional equation of motion 18 examined and $1 \mathrm{t}$ is concluded that in order to determine the energy slope (S) (and thence the shear stress and shear velocity) it is essential to evaluate density, inertia and kinetıc energy terms as well as surface slopes. Although the density te $\mathrm{rm}$ is much smaller than the other terms it is important at periods of low slack-water.

Measurements of the various terms are described and attention is drawn to the difficulties arising in the case of the surface slopes. Comparison is then made between the values of the shear velocity as predicted from the energy slope and those obtained using velocity traverses throughout the depth and with measurements of velocity at three fixed positions near to the bed. Finally consideration is given to the relationship between the cross-sectional mean velocity $(\overline{\bar{U}})$, the depth-mean velocity $(\bar{U})$ and velocity at $3 \mathrm{ft}$. above the bed $\left(\mathrm{U}_{3}\right)$ and the shear velocity obtained from the energy slope. It is concluded that there is good linear correlation of each of the se velocities ( $\overline{\bar{U}}, \bar{U}$ and $U_{3}$ ) with the shear velocity throughout the tidal cycle except for the period around low slack-water. 


\section{INTRODUCTION}

The shear velocity $\left(u_{*}\right)$ is one of the basic parameters which govern the vertical distribution of sediment in uni-directional flow. It is to be expected that $u_{*}$ will be as important in the case of tidal flow. However, in this case the variation of the shear velocity with time can be quite rapid; this added complication implies that the problem is essentially more complicated for tidal flow than for the uni-directional case.

Recent research by the junior author has shown that the distribution of sediment in a tidal flow can be described by equations similar to those of the uni-directional flow, e.g. the equation as used by Rouse, Vanon1, Einstein, (ref. 1,2 and 3) provided the suspension exponent $\mathrm{z}=\mathrm{W} / \beta \mathrm{Ku}_{*}$ is adjusted for the temporal variation of $u_{*}$ (W 1 s the fall velocity of the sediment particles,

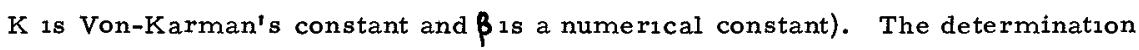
of $u_{*}$ for the case of tidal flows is therefore important for the description of sediment distribution which, in turn, is required if a quantitative analysis of the sediment transport within a tidal area is to be made.

\section{ANALYSIS}

The longitudinal equation of motion in two dimensions can be written for an estuary (after Agnew ${ }^{4}$ ) as.

$$
\frac{d}{d t}(p U)+\frac{\partial p}{\partial x}-\frac{\partial \mathcal{V}}{\partial y}=0
$$

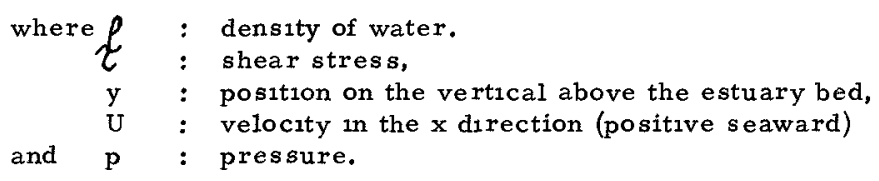

If the vertical density gradient and the velocity in the y direction are 1 gnored and atmospheric pressure is as sumed constant then the pressure gradient along the estuary can be written. 


$$
\frac{\partial p}{\partial x}=-\rho g l+g(H-y) \frac{\partial \rho}{\partial x}
$$

where I : water surface slope (positive ebb direction)

and $\mathrm{H}$ : water depth.

Substituting equation (2) into equation (1) and expanding the first term (Ignoring variations of density with time) gives

or

$$
\frac{\partial \mathrm{u}}{\partial \mathrm{t}}+\frac{\mathrm{u}}{\partial \mathrm{u}}+\frac{\mathrm{u}^{2}}{\rho} \frac{\partial \rho}{\partial \mathrm{x}}-\mathrm{gl}+\frac{\mathrm{g}}{\rho}(\mathrm{H}-\mathrm{y}) \frac{\partial \rho}{\partial \mathrm{x}}-\frac{1}{\rho} \frac{\partial \tau}{\partial \mathrm{y}}=0
$$

$$
\frac{1}{g} \frac{\partial U}{\partial t}+\frac{\partial}{\partial x}\left(\frac{U^{2}}{2 g}\right)+2 D\left[1-\frac{y}{H}+\frac{U^{2}}{g H}\right]-\frac{1}{\rho g} \frac{\partial \zeta}{\partial y}=1
$$

where D : density slope $=\frac{H}{2 \rho} \frac{\partial f}{\partial x}$

Substituting $\eta=y / H$ and assuming $U^{2} / g H$ is very much less than unity, equation (4) can be written:

$$
A+F+2 D(1-\eta)-\frac{1}{\rho g H} \frac{\partial \tau}{\partial \eta}=I
$$

Integrating equation (5) throughout the depth (1. e. from $\eta=0$

to $\eta=1.0)$ and as suming the shear stress at the surface 1 zero gives

$$
\begin{aligned}
& \frac{\tau_{\mathrm{b}}}{\rho \mathrm{gH}}=\mathrm{S}=1-\mathrm{D}+\mathrm{A}_{1}+\mathrm{F}_{1}
\end{aligned}
$$

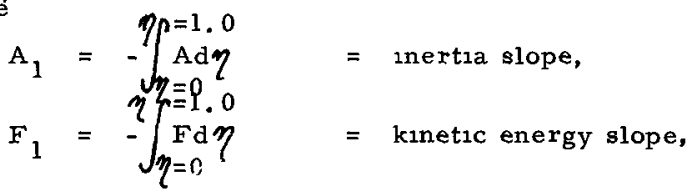

and $\tau_{\mathrm{b}}=$ sh ar stress at the bed.

Now the shear velocity

$$
u_{*}=\left(\tau_{\mathrm{b}} / \rho\right)^{\frac{1}{2}}
$$

so equations (6) and (7) show that the shear stress at the bed and the shear velocity are dependent upon density $(D)$, inertia $\left(A_{1}\right)$ and kinetic energy $\left(F_{1}\right)$ terms as well as surface slope (I). In order to determine the variation of $u_{*}$ throughout a tidal cycle it is therefore necessary (a) to measure the water surface slope along the estuary, (b) to determine the variations of velocity both along the estuary and with time in order to calculate the inertia and 
kinetic energy slopes, and (c) to measure the longitudinal variation of density.

In order to determine the inertia and kinetic energy terms $A_{1}$ and $F_{1}$ the variation throughout the depth of each of the terms $A$ and $F$ is required. It is convenient to consider $A$ and $F$ to increase linearly from zero at the bed to some values $A_{b}$ and $F_{b}$ at some small distance above the bed given by $\eta=\eta_{1}$, and then to increase to surface values of $A_{S}$ and $F_{s}$ respectively according to some chosen mathematical relationship. This arrangement is indicated in Fig. 1.

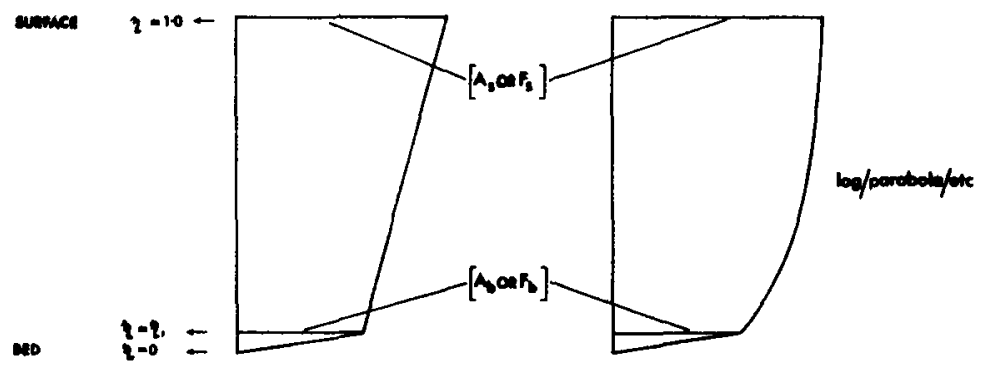

Fig. 1. Assumed variation of inertia and kinetic terms with depth

The simplest relationship to be assumed between $\eta=\eta_{1}$ and $\eta=1.0$ is a linear one (Fig. 1 a) and the integration of the terms $A$ and $F$ throughout the depth then give:

$$
\begin{aligned}
A_{1} & =-A_{b}\left(1-\frac{1}{2} \eta_{1}\right)-\frac{1}{2}\left(A_{s}-A_{b}\right)\left(1-\eta_{1}\right) \\
\text { and } F_{1} & =-F_{b}\left(1-\frac{1}{2} \eta_{1}\right)-\frac{1}{2}\left(F_{s}-F_{b}\right)\left(1-\eta_{1}\right)
\end{aligned}
$$

The special case of uniform velocity distribution from bed to surface is easily obtained from equations (8) and (9) with $\eta_{1}=0, A_{s}=A_{b}=A_{m}$ and $\mathrm{F}_{\mathrm{s}}=\mathrm{F}_{\mathrm{b}}=\mathrm{F}_{\mathrm{m}}$ as 
$\begin{aligned} A_{1} & =-\frac{I}{2}\left(A_{s}+A_{b}\right)=-A_{m} \\ \text { and } F_{1} & =-\frac{1}{2}\left(F_{s}+F_{b}\right)=-F_{m}\end{aligned}$

It is of interest to compute the val ues of inertia and kinetic energy terms when various distributions throughout the depth are assumed and to compare these values with the linear case given by equations (8) and (9). For this purpose a number of cases are presented below and because the same relationships are true for $A_{1}$ and for $F_{1}$ only the formulae for $F_{1}$ are given.

\section{Log curve with 2 points known}

If the value of $F$ near the bed and at the surface are known and the distribution of $F$ is assumed to be logarithmic the expression for $F_{1}$ is found to be

$$
F_{1}=-F_{b}\left(1-\frac{1}{2} \eta_{1}\right)-\frac{\left(F_{s}-F_{b}\right)}{\ln \left(1 / \eta_{1}\right)}\left[\ln \left(\frac{1}{\eta_{1}}\right)-1+\eta_{1}\right]
$$

\section{Log curve with 3 points known}

In this case it 18 assumed that a third value of $F$ is known $F_{1}$ at $\eta_{1}$ as well as $F_{b}$ at $\eta_{1}$ and $F_{s}$ at $\eta=1.0$. If the distribution is assumed to be linear between the bed and $F_{b}$ and then two logarithmic curves between $F_{b}$ and $F_{1}$ and $F_{1}$ and $F_{S}$ then the expression for $F_{1}$ becomes

$$
\begin{aligned}
F_{1} & =F_{b} \frac{\eta_{1}}{2}-F_{b} \eta_{1}-\frac{\left(F_{1}-F_{b}\right)}{\ln \left(\eta_{1} / \eta_{1}\right)}\left[\eta_{1} \ln \left(\frac{\eta_{1}}{\eta_{1}}\right)-\eta_{1}+\eta_{1}\right] \\
& -F_{1}\left(1-\eta_{1}\right)+\frac{\left(F_{1}-F_{s}\right)}{\ln \left(1 / \eta_{1}\right)}\left[\ln \left(\frac{1}{\eta_{i}}\right)-1+\eta_{1}\right]
\end{aligned}
$$

\section{Parabolic with 1 point known}

The surface value is $F_{s}$ and the distribution is as sumed to be parabolic between the bed and the surface.

$$
F_{1}=-\frac{2}{3} F_{S}
$$




\section{Parabolic with 2 points known}

In this case values of $F_{s}$ and $F_{b}$ are as sumed to be known at $\eta=1.0$ and $\eta_{1}$ respectively. The distribution of $F$ is assumed to be linear from the bed to $\eta=\eta_{1}$ and then parabolic to the surface with the requirement that the parabola is tangential to the linear distribution at $\eta=\eta_{1}$ 1. e. no discontinuity in slope at $\eta=\eta_{1}$. Then

$F_{1}=-\frac{1}{2} F_{b} \eta_{1}-F_{0}\left(1-\eta_{1}\right)-\frac{2}{3} \frac{\left(F_{s}-F_{o}\right)}{\sqrt{1-\eta_{0}}}\left[\left(1-\eta_{0}\right)^{3 / 2}-\left(\eta_{1}-\eta_{0}\right)^{3 / 2}\right]$

where $I_{0}$ and $\eta_{0}$ are given by the equations

$$
\begin{aligned}
\left(F_{b}-F_{o}\right)^{2} & =\frac{\left(F_{s}-F_{o}\right)^{2}}{\left(1-\eta_{o}\right)}\left(\eta_{1}-\eta_{o}\right) \\
\text { and }\left(1-\eta_{o}\right) & =\frac{\left(F_{s}-F_{o}\right)^{2}}{2 F_{b}\left(F_{b}-F_{o}\right)}
\end{aligned}
$$

For consideration of the differences between the various relationships considered it was decided to use typical (maximum) values of the velocities in the estuary reach under study and compute the various values of $E_{1}$ obtained using equations (9), (11), (12), (13), (14) and (15).

The surface velocity at either end of the reach under consideration was taken to be 3.0 and $5.0 \mathrm{ft}$. $/ \mathrm{sec}$. The variation of velocity with depth was taken as logarithmic and the shear velocity was taken as constant along the reach and equal to $0.24 \mathrm{ft}$. $/ \mathrm{sec}$. The velocity near the estuary bed (1.e. $\left.\eta=\eta_{1}=0.05\right)$ was then calculated from the logarithmic velocity distributions and yrelded values of 1.21 and $3.19 \mathrm{ft}$. / sec. The mean value of the velocity over the vertical at either end of the reach was also calculated at 2.4 and 4. $4 \mathrm{ft}$. / sec. From these figures it is seen that $F$ is proportional to $\left(5^{2}-3^{2}\right)$ 1. e. 16 while $F_{b}$ is proportional to $\left(3.19^{2}-1.21^{2}\right)^{3}$ 1. e. 8.7. If $F$ is determined from the depth-mean velocity, then $F$ is proportional to $\left(4.4^{2}-2.4^{2}\right)$ 1.e. 13.6 . 
The differences between the various assumed vertical profiles for $F$ can now be compared by using the values of $F_{s}$ and $F_{b}$ quoted above. The linear distribution (equation (9)) gives $F_{1}$ proportional to 12.57 while the simple parabolic case (equation (14)) gives $F_{1}$ proportional to 10.7. The more complicated parabolic distribution (equation (15)) gives $F_{1}$ proportional to 13.06 whilst the single log curve (equation (12)) gives $F_{1}$ proportional to 13.48 .

If the value of $F$ is calculated for various elevations above the estuary bed from the two velocity profiles as measured throughout the depth, then the depth-mean value of $F$ is found to be proportional to 13.5. Thus, as expected the single log curve agrees most closely with the depth-mean value of $\mathrm{F}$. The simple linear form is, however, only about $7 \%$ less than the much more complicated log expression. The one point parabolic curve shows the worst agreement. The use of the depth-mean velocity to calculate $F$ shows excellent agreement with the depth-mean value of $F$. Thus the use of the depth-mean velocity to calculate the $F_{1}$ term would appear justifiable.

If the velocity profile does not increase regularly from the bed to the surface (e.g. in certain flood profiles in stratıfied estuaries the surface velocity is lower than at mid-depth) then the value of $F_{1}$ will be given by equation (13) with $\mathrm{F}_{1}>\mathrm{F}_{\mathrm{s}}$. In order to examine this type of distribution, the surface velocity at either end of the reach was reduced from 3.0 and $5.0 \mathrm{ft}$. $/ \mathrm{sec}$. to 1.8 and $3.0 \mathrm{ft} . / \mathrm{sec}$. respectively. The velocity profile is as sumed to reduce logarithmically from the surface to mid-depth, the latter has the same value as previously 1.e. 2.59 and $4.58 \mathrm{ft}$. / sec. and the distribution below mid-depth is as before. Therefore $F_{S}$ is now proportional to 5.75 while $F_{1}$ in equation (13) is proportional to 14.3 with $\eta_{1}$ equal to 0.50 and $\eta_{1}=0.05$. With these values, $F_{1}$ is found to be proportional to 10.64 , while the value of $F$ computed from the depth-mean velocity is found to be 10.5. The depth-mean value of F computed at various elevations above the bed from the assumed log velocity profiles 1 found to be $10 / 6$. 
Thus again the value of $F_{1}$ computed from the assumed log distribution of $F$ gives excellent agreement with the depth-mean value of $F$ from the velocity profiles. This could be expected since a log curve was chosen for the depth variation both of velocity and of $F$. There is again close ag reement between $F$ 'computed from the depth-mean velocity and the depthmean value of $F$. The depth-mean velocity will therefore be used to compute values of the $F_{1}$ term in equation (6).

\section{Consideration of the vertical velocity term in the equation of motion}

In deriving equation (6) it was assumed that the vertical velocity could be ignored. For a similar study Sato, Kıkkawa and $\mathrm{K}_{1 \mathrm{sh}}{ }^{5}$ included this term and found it to be of importance at certain stations of the River Tone. In the case of the Narrows of the River Mersey it was found that this term is relatively small and unimportant. It is possible that at its maximum value it is of the same order as the value of $D$, however it is only large when the value of $\mathrm{S}$ is large and is in general less than $10 \%$ of the value of $\mathrm{S}$. The value of $D$ on the other hand is constant throughout the tidal cycle and is therefore important when the value of $S$ is small, around the periods of slack water. 


\section{MEASUREMENTS}

The previous analysis indicates that four basic quantities, I, $A_{1}$, $F_{1}$, and $D$, have to be determined from field observations in order to calculate the bed shear. The necessary field work has formed part of a much larger research programme (which is still in progress) for the investigation of the water and sediment circulation patterns of the Mersey Estuary. This research is sponsored by the Mersey Docks and Harbour Board.

The field observations of velocity, density etc. from which the four basic quantities are determined have been made in an area of the Mersey known as the Narrows. The estuary here runs a straight course for several miles (cross-flow is thus a minimum) and is narrow enough to be unaffected by coriollis forces. It is however, wide enough to be considered two dimensional. The reach is also free of rapid changes in cross-section and the estuary is well mixed so that the vertical salinity distribution in the Narrows is almost uniform (1.e. less than $2 \%$ difference between surface and bed). The measurement of $I_{1} A_{1}, F_{1}$ and $D_{1 n}$ this research are now considered separately.

\section{(1) Water Surface Slope (I)}

In the absence of cross-flow, Corriollis and wind forces, the term I can be taken as constant across the width of the estuary. Its magnitude was found initially by an examination of the automatic tide recordings at Gladstone Dock and Princes Pier. These gauges are both situated on the East side of the river at the ends of the reach under consideration. A preliminary examination of water surface slope from the tide gauge records indicated some very odd results e.g. large flood slopes in the middle of the ebb tide. 
Each tıdewell was then critically examined. At Princes stage it was found that the tidewe11 (an 8" O. D. pipe) was situated in a falrly fast flowing stream. Research work by Perry 6 \& 7 indicated that this particular tide gauge was subject to an error which caused the water surface level inside the well to be greater than that outside and this error depended on the magnitude of the flow velocity past the tide gauge orifice. Meanwhile Lennon ${ }^{8}$ had demonstrated that both Princes and Gladstone tide gauges were subject to a salinity stratification i.e. the density of water in the well at high water decreased from the low water salinity value at the surface to the high water salinity value in the region of the orif $1 \mathrm{ce}$. Thus at high water the level inside the tidewell was greater than in the tideway. A further difference of level between the tidewell and tideway can also be caused by the presence of silt which enters the well from the tideway on the flood tide. In the limat the silt completely blocks the tidewell orifice and the water is unable to escape. Further errors can also result from the automatic recording equipment itself e.g. eccentric timing mechanısms and badly aligned pen carriages. Because of all the above mentioned difficulties the water surface slope was determined independently of the automatic tide gauge equipment and of the Princes tidewell.

A self-aligning engineers level was mounted on a floating pontoon attached to Princes Stage (a floating landing stage) at approximately 6-8ft. from a tide staff. The latter could be read to $\pm \frac{1}{4} 11$. Readings on the tide staff were taken continuously for a period of 30 seconds every 15 minutes. The height of collimation of the level was determined at slack water and checked during the course of the experiment. The water level was also read directly from the tide staff as a cross-check. 
The level at Gladstone was determined by using an electronic probe device which indicated the water level relative to the top of the well of the tide-gauge. Basically this instrument consists of a pointer attached to a surveyor's tape through which a current is passed, the other electrode usually being the well itself. As the pointer touches the water surface the circuit is completed and this is registered as a frequency-change in an audio-signal transmitted from the instrument. This instrument could be read to $-1 / 16$ in. The salinity of the water in the well was measured at slack high and low water as also was the salinity in the tide-way at the orifice level. Errors due to silt were eliminated by cleaning the well, the day previous to the tests. There is little velocity past this well except when ships are entering Gladstone Dock, the level in the tideway is therefore assumed to be equal to that in the well, less the salinity error.

The tide curves at each station were then plotted and smoothed(particularly the Gladstone curve near high water when the passage of ships into the Dock caused the levels to be slightly reduced). The water level at Gladstone was then corrected for the salinity error using the mean value of the salinity (1. e. density) inside and outside the well. The difference at any instant of time between this curve and that observed at Princes is then the water surface slope along the reach (I)

\section{(ii) Inertia Slope $\left(A_{1}\right)$}

In three-dimensional flow this term will not be a constant across the estuary since the lateral distribution of velocity (U) 1 s not constant. In the two-dimensional case the variation of $A_{1}$ across the estuary is ignored and the variations of the mean velocity are considered. Thus for the present calculation A will be determined from the cross-sectional mean velocities at the surface and near the bed. 
Several days fleld observations of the water velocity near the estuary bed and at the surface were avallable for a position in the centre of the river, midway between Princes Pler and Gladstone Dock. These observations were collected as part of the general research work in progress in the Mersey estuary. The vebcities were measured using a Kelvin Hughes Direct Reading Current Meter. These field results were plotted out against time and the surface and near-bed velocities taken off the resulting graphs at half-hourly intervals. These velocities were then plotted against high water level (similar to the effect of range in the Mersey) so that a set of velocities could be obtained at half-hourly intervals for a tide of approximately $27.5 \mathrm{ft}$. H. W. (L. B. D.).

From the work of Burke 9 it is possible to relate the depth-mean velocity $(\bar{U})$ at the position under consideration to the cross-sectional mean velocity

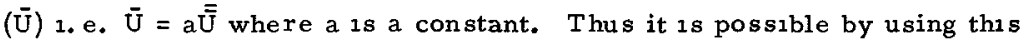
relationship to reduce the half-hourly surface and near bed velocities to the equivalent cross-sectional mean velocity.

Values of $A_{b}$ and $A_{s}$, every half hour were then calculated from the reduced (cross-sectional mean) velocities. $A_{1}$ at each time interval then follows from equation (8) with $\eta_{1}=0.05$.

(111) Kinetic Energy Slope $\left(F_{1}\right)$

This quantity will also vary across the width of the estuary, depending on the velocity distribution across the width. For the case of two dimensional flow the cross-sectional mean velocity $(\overline{\bar{U}})$ will again be used to compute $F_{1}$. In the case of a real estuary the value of $F_{1}=\frac{\partial}{\partial x}\left(\bar{U}^{2} / 2 g\right)$, will not be equal to the mean value of $F_{1}$, for the cross-section and a factor $(\alpha)$ must be used 
to account for this discrepancy. The constant $(\alpha)$ can vary from $1.0-2.0$ depending on cross-sectional shape. In the case of the Mersey, in the area of the Narrows, the constant will be of the order of 1.1 and because of this, the correction will not be applied (1.e. $\alpha_{1 s}$ taken as 1.0$)$. In order to compare the two dimensional equation with river observations, a position was chosen at which the mean depth is close to the cross-sectional mean-depth. Crosssectional effects should therefore be a minimum.

The calculation of $F$ using $F_{b}$ and $F_{s}$ has not been possible since this requires velocity measurements opposite Princes Pier, which is the centre of ship passenger traffic for Liverpool, Bırkenhead, North Wales and the Isle of Man. Use has therefore been made of the cross-sectional mean velocity $(\overline{\bar{U}})$ in order to calculate $F$. The value of $\overline{\bar{U}}$-every half hour throughout a tidal cycle at various cross-sections along the river, including Gladstone and Princes, have been computed by Burke ${ }^{9}$ using the continuity equation. The value of $F_{1}$ at half-hourly intervals through a tidal cycle can thus be calculated as the difference between $\left(\overline{\mathrm{U}}^{2} / 2 \mathrm{~g}\right)$ at Princes and Gladstone. Adjustments to $\overline{\bar{U}}$ for diffe rent tidal ranges are also possible since the variation of $\overline{\bar{U}}$ with high water level (or range) is linear in this reach of the Mersey. In the present computations $F_{1}$ has been calculated for a high water level of just over $27 \mathrm{ft}$. 1. e. similar to the tides for which the surface slope was measured.

\section{(1v) Density Slope (D)}

This term indicates the presence of a longitudinal density gradient in the Mersey which is always present due to the mixing of fresh and saline water. Its order of magnitude in the case of the Mersey is small but it can be significant when the terms I, A and F are small (e.g. slack low water). 
In order to indicate the relative magnitude of all the terms ( $I, A_{1}$ and $F_{1}$ ) these have been expressed in terms of D (F1g. 2). Thus on large Spring Tides the total energy slope can be the order of twenty times the density effect, but on Neap Tides with a large freshwater flow this could be reduced to less than ten times the density effect. For the purposes of the present calculation, the density term is taken as solely due to the variation of salinity along the estuary (1. e. depth variation is ignored) and to be a constant throughout the tide.

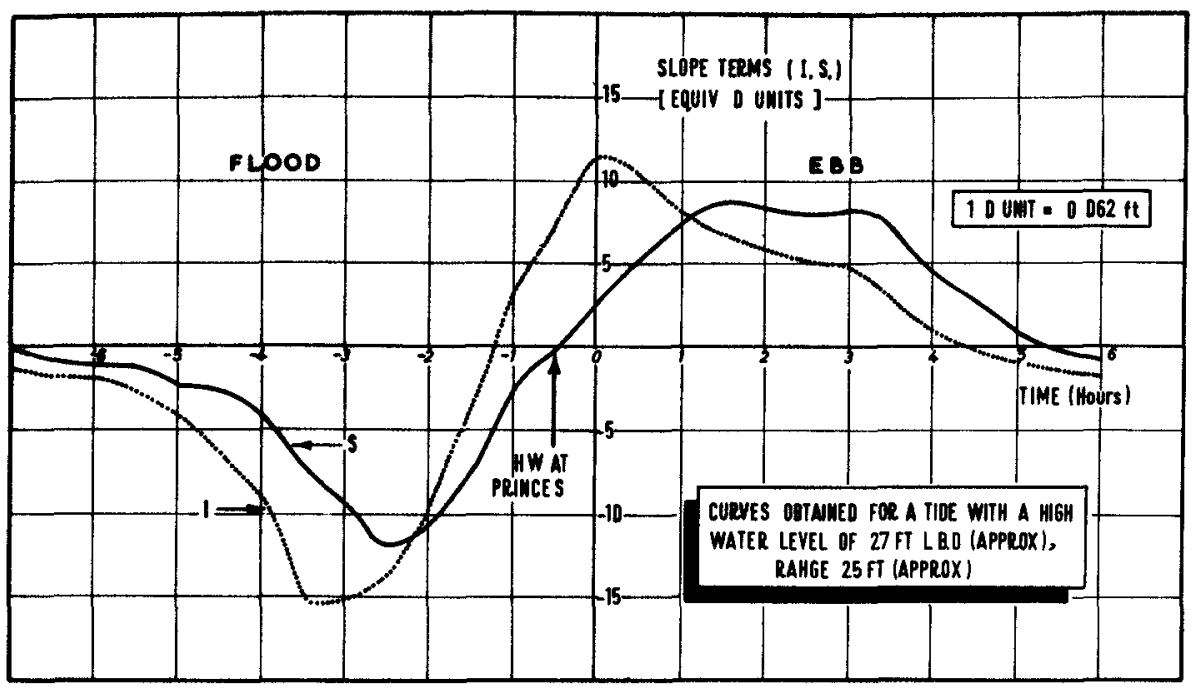

F1g. 2. Variation of Water Surface and Energy Slopes Throughout the Tidal Cycle 
Longitudinal salinity data obtained by Wallingford ${ }^{10}$ for a model of the Mersey Estuary was examined and a longitudinal profile of mean salinity produced. From this, a mean longitudinal salinity gradient was produced. This was then combined with the centre-line mean-depth of the reach to produce an overall mean figure for the density term $D$. This amounted to a head difference over the Princes to Gladstone Reach of $0.062 \mathrm{ft}$. in the horizontal distance of $16,000 \mathrm{ft}$.

The energy slope (S) can now be calculated from equation (6) using the components $I, A_{1}, F_{1}$ and $D$ and this is shown in Fig. 2. Once $S_{1 s}$ known, the shear on the bed $\left(\tau_{b}\right)$ can be calculated as also can $u_{*}=\left(\tau_{b} / p\right)^{\frac{1}{2}}$ as shown in Fig. 3.

\section{Shear velocity using velocity profiles}

The value of $u_{*}$ thus obtained can also be compared with measurements taken in the field. A position on the cross-section midway between Gladstone and Princes was selected such that the depth at mean tide level was approximately equal to the mean cross-sectional depth at mean tide level. Measurements of the water velocities were made on a vertical from the surface to approximately $3 \mathrm{ft}$. above the estuary bed. This was done using the direct reading current meter. These velocity transverses were made at approximately half-hourly intervals. The velocities in the region $61 \mathrm{n}$. $-3 \mathrm{ft}$. above the bed were measured using three Ott Mark V Arkansas Current Meters mounted on a vertical freely pivoting rod which was held within a triangular framework. The Ott Meters were connected to a control unit which enabled the three meters to be read simultaneously. The length of time for which the velocities were recorded could be varied to any time interval. 
In the case of the present observations a time interval of 10 seconds was used which appears to have been too low since the included results for $u_{*}$ show a large scatter. Some of this scatter has been reduced by averaging all the results taken within each fifteen minute time interval. The shear velocity is obtained from the results by making a semi-log plot of the velocities against height above the bed, as was done by Lesser ${ }^{11}$. The same technique was used with the vertical profiles obtained with the D. R. C. M. except that the semi-log plots were confined to below mid-depth so that any wind, ship effects etc. were avoided. The comparison between the river results and those from equation (7) are shown in Fig. 3.

Bowden ${ }^{12}$ has suggested that $u_{*}$ can be related to the depth-mean velocity in a linear fashion i. e. $u_{*}=k \bar{U}$. In order to examine the relationship between velocity and $u_{*}$, the velocity at $3 \mathrm{ft}$, above the estuary bed $\left(\mathrm{U}_{3}\right)$, the depth-mean velocity and the cross-sectional mean velocity were plotted aganst time. Three values of $k$ were determined from these plots such that the sum of the squares of the errors in prediction was a minimum i.e. $\sum\left(\mathrm{kU}-\mathrm{u}_{*}\right)^{2}$ was a minımum (with $U$ equal to $U_{3}, \overline{\mathrm{U}}$ and $\overline{\overline{\mathrm{U}}}$ in turn). The three values found were $k_{1}=0.077, k_{2}=0.052, k_{3}=0.054$, for the velocity at $3 \mathrm{ft}$. above the bed, the depth mean and the cross-sectional mean respectively. A measure of the best relationship of the three is provided by the term $\sum\left(\mathrm{kU}-\mathrm{u}_{*}\right)^{2}$, it was found that the cross-section mean velocity provided the best fit. The comparison of the three values of $u_{*}$ using the values of $U_{3}, \bar{U}$ and $\overline{\bar{U}}$ with that value of $u_{*}$ calculated from the energy slope method is shown in Fig. 4.

\section{DISCUSSION OF RESULTS}

The comparison between $u_{*}$ computed from the energy slope method and from the tripod results (Fig. 3) is seen to be reasonable. It is felt that much of the scatter on the tripod results is due to two main causes. Firstly, the timing interval for the Ott current meters was too low. This enabled large velocity fluctuations, and thus fluctuations in shear to be recorded. Secondly the two calculations of $u_{*}$ from the velocities at $6 "$ and $12^{\prime \prime}$ and the velocities at $12^{\prime \prime}$ and $27^{\prime \prime}$ indicate that the top Ott meter (27") may have 


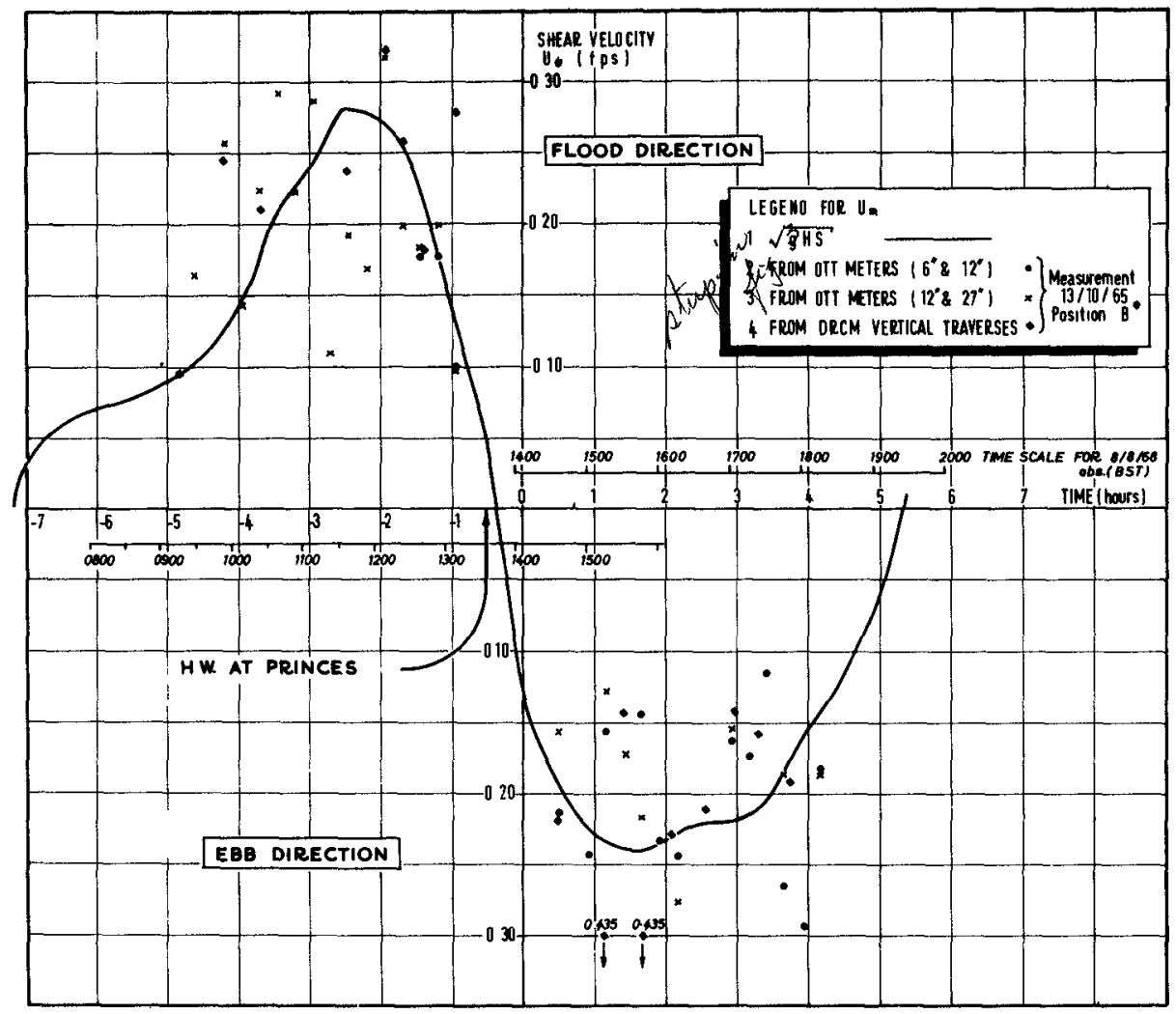

Fig. 3. Comparison between measured values of shear velocity with those obtained from the energy slope

been affected by the supporting framework of the tripod rig. If this $1 \mathrm{~s}$ so some re-design of the framework will be necessary. The question of velocity fluctuation can be overcome by a longer timing interval. Another possible reason for the values of $u_{*}$ obtained from the meters at $12^{\prime \prime}$ and $27^{\prime \prime}$ generally being too small may be that the meter at $27^{\prime \prime}$ had a different blade pitch than the other two meters and this may cause it to react differently to any turbulence. 
The shape of the $u_{*}$ curve (from the energy slope) is seen to closely follow the shape of the velocity distribution near the bed. However, the water surface slope is seen to be out of phase with both the $u_{*}$ and the velocity curves, particularly on the ebb tide.

If the velocity is used to determine $u_{*}$ by assuming a linear relationship $\left(u_{*}=k U\right)$ i. e. bed roughness 18 as sumed constant, then the cross-sectional mean velocity, rather than the velocity near the bed, is found to be a better fit for $u_{*}$ as calculated from the energy slope. Thereason for this is probably the uncertainty of the position of the D. R. GM. near the estuary bed; the averaging over the vertical etc. for the mean velocities tendang to reduce these sort of effects. The reasonable fit of the cross-sectional mean velocity to the $u_{*}$ curve (except at low water) does however mean that the mean velocity could be used to determine the shear velocity in those areas remote from 1 and (e.g. Liverpool Bay) where it is not possible to measure the water surface slope etc. and where density effects are small. These velocities could be obtained by field measurements or even by computation if an accurate mathematical model is avaılable.

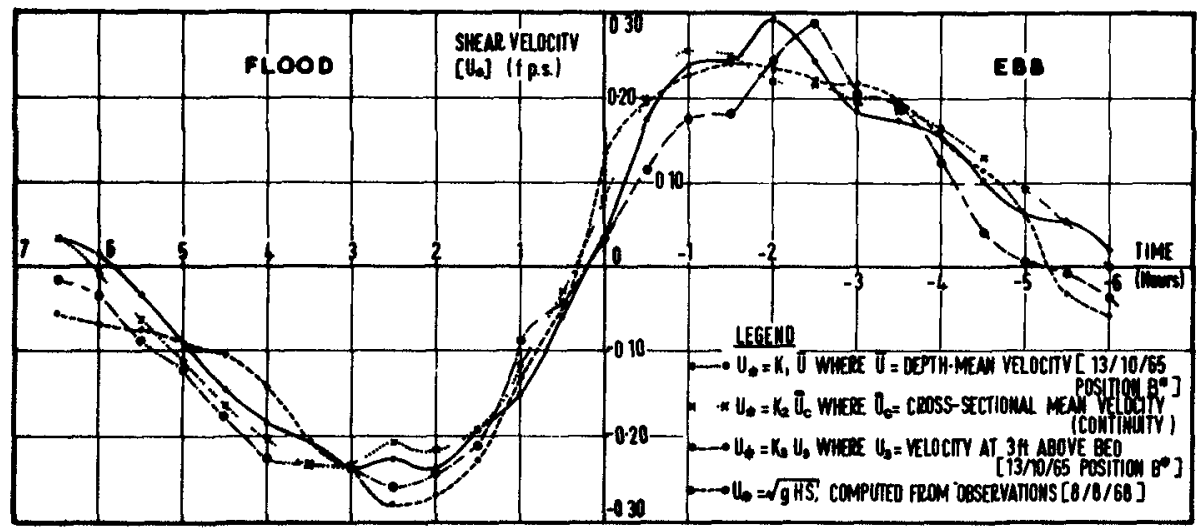

Fig. 4. Comparison between shear velocity obtained from velocity near the bed, depth-mean velocity and cross-sectional mean velocity 
The results also indicate that $u_{*}$ can be found for an estuary without taking many field observations. The water surface slope and density terms can be measured at the shore, while the kinetic and inertia effects could be obtained using velocities computed by applying the continuity equation to the estuary. This would produce the cross-sectional mean velocity $(\overline{\bar{U}})$ from which the $A$ and $F$ terms could be found.

\section{ACKNOWLEDGMENTS}

The work described is part of a general investigation sponsored by the Mersey Docks and Harbour Board. The authors are therefore pleased to acknowledge the help of the Board, in providing vessels and personnel, and the help of members of the University Civil Engineering Department. Thanks are especially due to Messrs. J. A. Nickson, C. Hewitt and M. O'Dell for their help with the field observations.

\section{NOT ATION}

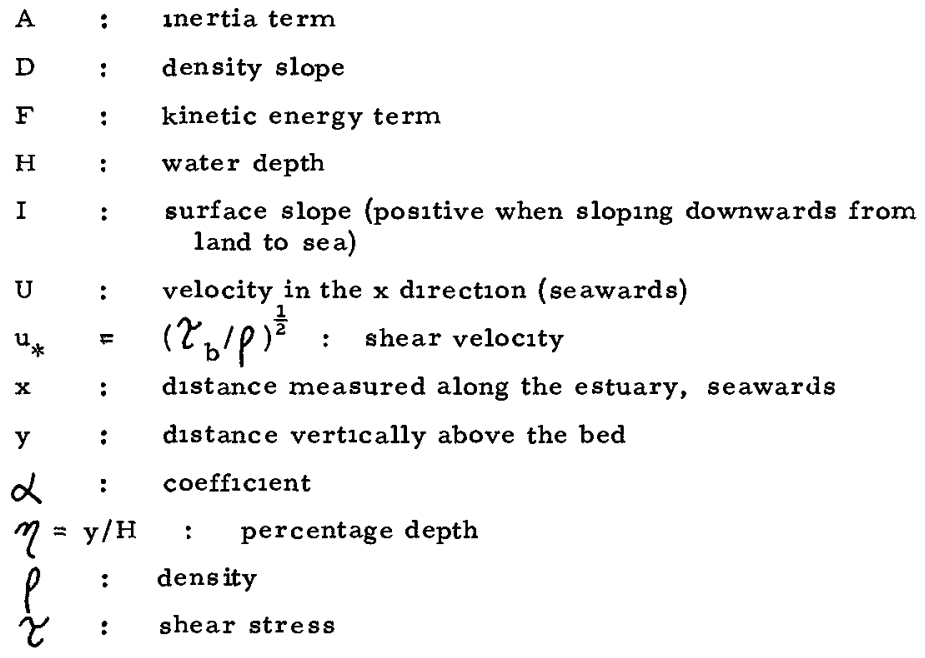

Subscripts -

b : near the bed

s : surface

1 : intermediate position 


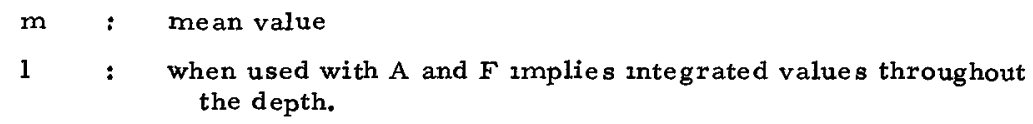

\section{REFERENCES}

1. Rouse, H. "Modern conceptions of the mechanics of flurd turbulence" Trans. A. S. C. E. Vol. 102, 1937, Fig. 30 p. 536.

2. Vanoni, V.A. "Transportation of suspended sediment by water" Trans. A. S. C. E. Vol. 1946, pp.67-102.

3. Einstein, H. A. "The bed load function for sediment transportation in open channel flows". United States Dept. of Agric. Tech. Bull. No. 1026, Sept. 1950.

4. Agnew, R. "Estuarıne currents and tidal streams" Proc. 8th Coastal Eng. Conf. 1960, Chapter 28, pp. 510-535.

5. Sato, S., Kikkawa, H. and Kishi, T. "On the hydraulic characteristıcs of the tidal reach of the Tone River" Paper A6, Proc. I. A. H. R., The Hague, 1955.

6. Perry, J. G. "Hydrodynamic Studres on tide gauges" University of Liverpool, M. Eng. Thesis 1967.

7. Halliwell, A. R. , and Perry, J.G. "Errors in tide gauges" Dock and Harbour Authority, Vol. XI,VIII, February 1968, pp. 305-308.

8. Lennon, G. W. "The behaviour of a stilling well in the presence of pe riodic density varıations" University of Liverpool, Trdal Institute, Internal Report No. 7.

9. Burke, C. "Velocities in tidal flows" M. Eng. Thesis, Liverpool University, August 1966.

10. D. S. I, R, Hydraulic Research Station, 2nd Internal Report on the Mersey Investigation, June 1.959.

11. Lesser, $R, M$. "Some observations of the velocity profile near the sea floor". Trans. A. G. U. Vol. 32, No. 2, April 1951, pp. 207-211.

12. Bowden, K, F. "The mixing processes in a tidal estuary". Int. J. Alr Wat. Poll. Pergamon Press 1963, Vol. 7, pp. 343-356. 